\title{
Unravelling Consumer Responses to Omni-Channel Approach
}

\author{
Won-jun Lee ${ }^{1}$ \\ ${ }^{1}$ Cheongju University, Business Department, Cheongju, Korea, marketing@cju.ac.kr \\ Received 24 January 2019; received in revised form 9 July 2019; accepted 1 October 2019
}

\begin{abstract}
Retailers begin to create new channel systems to meet changing market environments and innovative information technologies. The growing consumer need and market demand for online sales mean that traditional retailers need to create new integration in their distribution system to serve customers through multiple channels. However, building a successful omni-channel system leads to many challenges. The challenges arise from which customer values perceived by customers. The overall understanding of consumers under the new retail environment is still missing in the literature, and this study conducts an empirical study to close the gap. The author investigates the impact of omni-channel characteristics on customer satisfaction in the context of today's retailing. The findings of this research indicate that although some characteristics of omnichannel have direct impacts on customer satisfaction, relationships between other omni-channel characteristics and customer satisfaction are not supported. Among the constructs, integrated promotion and integrated information access are found to be significant, whereas other constructs are not. Also, the relationship between customer satisfaction and the intention to revisit omni-channel is supported positively. These results raise the need to review the existing strategy and view of omni-channel from the customer's perspective.
\end{abstract}

Keywords: Omni-channel, Multi-channel, Channel integration, Channel choice, E-retailing 


\section{Introduction}

With the rapid increase of online shopping, the retail environment is strongly affected. The growth of online shopping and e-commerce has been notable. In 2017, retail e-commerce sales worldwide amounted to 2.3 trillion U.S. dollars, and the dollars are projected to grow to a remarkable 4.88 trillion dollars in 2021 (see Figure 1) [35]. More consumers are turning their distribution channels into online shopping. For example in recent years, Cyber Monday shopping, which is an online event form the tail end of the Black Friday weekend, has far outpaced Black Friday's offline sales in the U.S. The rapidly growing importance and power of online e-commerce mean that traditional retailers need to create new channel systems to satisfy the customer through multiple channels no matter they are in online, offline or both. The boundary between online and offline shopping tends to disappear with the spread of efforts to do channel integration.

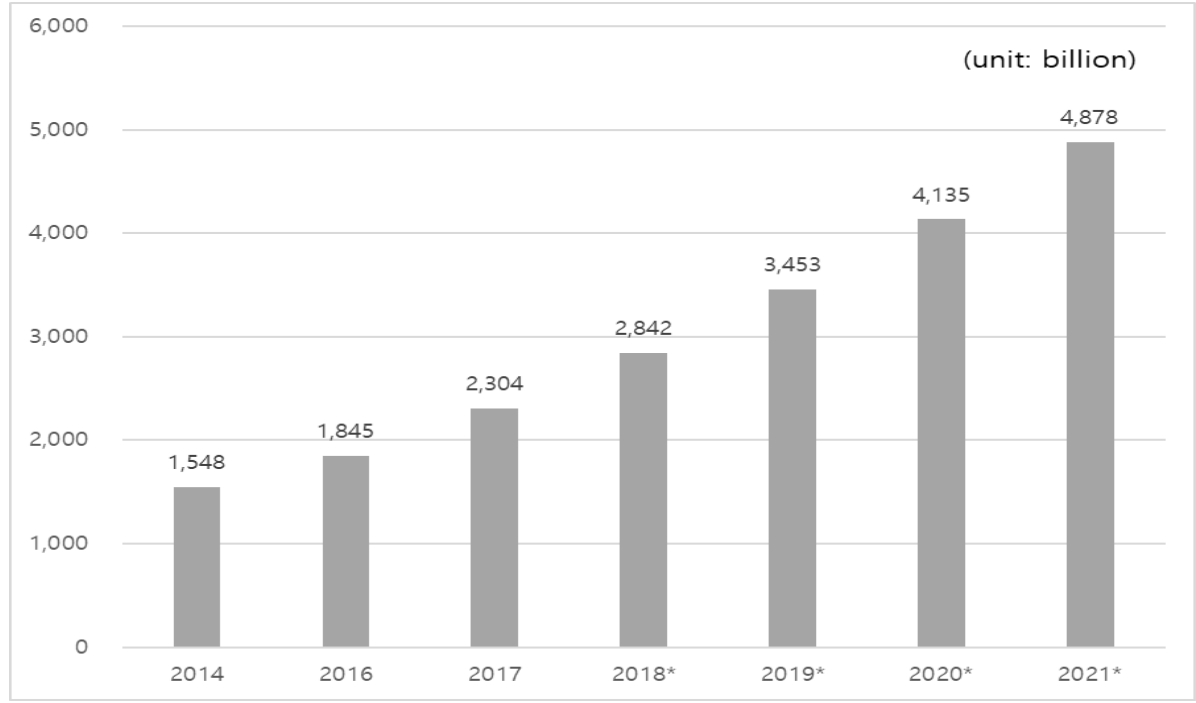

Figure 1: Retail e-commerce worldwide [35]

Accompanied by the widespread of e-commerce and the advance of innovative information technology in the retail business, major retailers have begun to integrate channels that they own, and use the new approach. New information technologies such as virtual screens, virtual mirrors-fitting rooms, self-service kiosks, QR codes, service robots, and smartphone apps are available in addition to mobile devices [22], [32], and firms are actively adopting these new technologies. For example, Starbucks does an excellent job of providing a seamless consumer experience across all channels by developing the Starbucks Reward app. Consumers have the option of checking and reloading their rewards card balance through their smartphone, the Starbucks website, or when they are in the physical stores. Any user profile change or balance is updated in real time, no matter where they are. In an attempt to go one step further and reshape the way retailers interact with their customers, firms have integrated these new channels (i.e., internet, mobile website, social media, Youtube, offline store) into their traditional operation [25]. Digitalization has a strong effect on retailing in physical stores. If a customer wants to buy, it does not matter anymore whether they are online or offline, and firms are seeking integration into omni-channel (OC).

OC retailing refers to the use of a variety of channels to interact with consumers and satisfy their needs. From a customer perspective, $\mathrm{OC}$ has enabled the consumers not only to purchase the products on the e-commerce website but also check the available stock of the physical store [18]. These integration efforts of multiple channels have attracted more attention as they are customer oriented activities and are expected to increase customer satisfaction and provide a better customer experience. According to the recent survey of business leaders in retailing, about $76 \%$ of respondents placed OC strategy as a top priority issue for future retailing [21]. They want to integrate the selling channels to enable an OC face to the customer more efficiently. The proliferation of OC has offered customers a new possibility to do communication and transaction with the retailer [7]. As a result, customers increasingly select integrated retailers for their transactions.

However, building an active OC leads to new challenges. For example, the growing number of multiple channels increases complexity from a customer point of view. It is highly important and urgent to understand how retailers can manage all touch points across all online and offline channels in an integrated manner to satisfy their customers by providing excellent shopping experiences. Despite the importance, the impact of OC's key characteristics on customer satisfaction or shopping experience has not been well evaluated. Relevant empirical studies are very scarce and sparse. Research on OC, which has recently begun to emerge, is limited in that it does not reflect new OC's unique characteristics and potential advantages. For example, in Han's research [13], customer satisfaction was analyzed under the OC environment, but the antecedents such as perceived difference, perceived value, 
authenticity brand relationship were variables that explain the general characteristics of the traditional distribution channel, not the OC. Therefore, this study aims to evaluate the influence of the characteristics of OC on customer satisfaction based on existing theoretical studies.

This paper is organized as follows: The next section is the theoretical literature reviews, and we discuss the characteristics and importance of OC. Section 3 presents a research model and hypotheses. Section 4 describes the data and methodology used in the research and provides a series of empirical results for the hypothesis test. Section 5 discusses the research implications, limitations, and need for future research work.

\section{Theoretical Background}

In this section, the advance of omni-channel and its influence is highlighted. First, the concept of omni-channel is identified based on previous research. Second, the relationships between consumer and omni-channel are reviewed.

\subsection{Advance of OC}

The development of a concept for $\mathrm{OC}$ retailing has emerged in practice very lately, and much research has been done recently on the subject [3], [20], [41]. OC is a cross-channel retail model that firms use to improve the consumer experience and to maximize the firm's performance. Although underdeveloped as an academic concept, ominous is Latin for 'all,' meaning 'all channels together' [20]. Thus, OC is a consumer-centric channel featuring a holistic shopping experience irrespective of the channels used [31].

Verhoef et al. defined $\mathrm{OC}$ as the synergistic retailing management method of the numerous available channels and touchpoints [41], in such a way that the consumer experience and marketing performance are optimized across channels. Frost and Sullivan defined $\mathrm{OC}$ as an integrated retailer offering seamless, effortless, high-quality consumer experiences, which occur within and between channels [11]. According to these academic definitions, the core component of $\mathrm{OC}$ is synergy and consumer experience through integrated management of various channels.

However, the concept of managing various channels is not entirely new. In the past, there have been multi-channel (MC) management and cross-channel (CC) management as a retail management technique for controlling various channels. MC, CC, and OC share similar characteristics. However, one of the key differences lies in the level of integration. $\mathrm{MC}$ is if two or more channel participants are used, but the interaction between channels is low while CC is a mix between MC and OC [3]. According to Ye et al. [47], MC is usually identified as the non-integrated business, while OC requires concrete and absolute integration. OC takes a broader perspective on the level of channel integration, considering not only the number of channels but the interactions between consumers and retailers [9]. An OC retailer is a company that provides any services to consumers anytime, anywhere by integrating its information, physical distribution, and consumer experience of all the channels.

Retailers' approach to digital channel makes additional differences. With all this radical influence, it is clear that retailers need insights into the changing role that the internet plays in the new channel system. For example, consumers who ended up buying a television in a physical store tend to start the internet search query [12]. Consumers expect to receive service on the channel of their service, whether it is e-mail, website, phone, social media, or face to face interaction in the physical store [34]. According to Verhoef et al. [41], retailers seeking to optimize performance for each channel adopt MC strategy, whereas retailers focusing on overall customer experience and performance across traditional and digital channels are practicing OC strategy.

\subsection{OC Consumer and Marketing}

The OC environment brings many changes to retailers. In the OC, consumers move freely between the physical store, online shopping mall, mobile device, and social commerce site. Thus, the new environment requires retailers to have in-depth integration across areas such as sales, marketing, stock management, order fulfillment, and returns so that the operations are streamlined with the marketing activities in the marketplace [26]. As a result, the complexity of marketing activities and customer understanding under the OC environment is further increased. For example, it involves the extensive use of information technologies to integrate resources from the online and offline channels, and order fulfillment process is no longer straighforward because offline retailing is overlapping with online retailing [3].

Despite this complexity, the increased use of $\mathrm{OC}$ is expected to benefit both the business and the customer. From the viewpoint of the retailer, how retailers manage consumer interactions and touch points in the presence of multiple channels is an essential issue in the retail marketing area. Retailers can improve product and service offerings through close interactions with consumers via multiple touch points and observations of consumer behaviors at these contact points. In OC environments, the interaction between a consumer and retailers is mainly in terms of product flow, information flow, and funds flow [8]. The OC retailers provide product and price information to the consumer, who then makes an order. The retailers use the order information to place the actual product to the place that 
consumers want. A well-structured OC can be cost-effective and responsive to consumer needs by making the three flows seamless.

This OC feature can also benefit consumers. OC consumers can acquire accurate information about product quality, terms and price, and availability that supports them to make a better purchase decision [6], [47]. Previous studies in this area aim mainly at understanding the drivers of consumers' channel choice by describing variables affecting consumers' different behavior in the presence of $\mathrm{OC}$. If a retailer understands what the drivers are of OC preference, it can provide a fortified satisfactory experience to the customers across the channels. Previous researches in this agenda aim at understanding the key drivers of channel choice behavior of customers by identifying variables that can explain. Those variables are based on channel attributes, consumer channel experience, social influence, and consumer heterogeneity [25]. They insisted that customer difference in psychographics and demographics make a difference in customer channel choice.

As a result, OC's success depends in part on technological development, but ultimately on consumer understanding. However, there is not much knowledge about consumers in the OC environment. For example, understanding the effects of emotional motivation, one of the most important motivations of shopping, is a new challenge. In general, consumers enjoy the pleasure of shopping, and they treat it as a recreational process [38]. Shopping as a source of recreation is more so for offline shoppers. In-store shopping experiences are treated as an information gathering exercise and sensory stimulation is viewed as a critical part of the search process [48]. Attractive visual merchandising also motivates consumers to stay more time and stimulate purchase [28]. Although the OC evolution is changing consumers' shopping experience, many retailers still fail to deliver a flawless emotional experience [33]. As a result, despite the previous research results, the study on the effect of OC on consumer satisfaction remains to be clarified, and additional research is needed.

\section{Hypothesis}

In this chapter, we propose the main hypotheses based on previous literature studies.

\subsection{OC and Satisfaction}

In general, the omni marketing mix is realizable only when utilizing both physical stores and e-commerce websites, and this online and offline integration has a positive effect on customer satisfaction [18]. The amount of marketing expenditure has a strong influence on the positive attitude of the customer. Promotion is no exception. The number of e-mails and catalogs sent to the customer contributes to explaining channel selection [2], these integrated promotions using e-mails and catalogs can accelerate the satisfactory experience of online and offline consumers [5] Many retailers still think offline advertising solely as a marketing tactic to increase sales. However, integrated promotion by smart retailers can lift both e-commerce sales and in-store sales, and the mixture of internet search advertising and display-related advertising offers a great marketing synergy [12]. The transition to OC marketing has increased the need for an integrated communication effort to enhance customer engagement [31]. Thus, this study hypothesizes as below.

\section{H1: Integrated promotion gives a positive influence on customer satisfaction.}

In the OC system, retailers need to offer a variety of options for discovering, buying, and returning products across the online and offline channel [19]. Retailers need to simultaneously ensure the availability of a product, meet different lead-times, and keep useful transaction information [14]. In order to provide various transactions related services, management of transaction information is essential, and better service will have a positive effect on customer satisfaction. Thus, this study hypothesizes as below.

\section{H2: Integrated transaction information management gives a positive influence on customer satisfaction.}

According to Fulgoni [12], consumers evaluate information search as the most crucial method in helping them save time and effort during the shopping experience. There is a lack of integration in marketing and pricing across all channels, and consumers are wary about pricing policy [32]. The integration of the product information and the price information will facilitate the retrieval of the information of the consumer and enhance the satisfaction. Besides, Venkatesan et al. [39] identify that travel costs can predict the visit of the second and third channel. If OC can offer the same price across the channels, customers will not need to make price comparisons through unnecessary shop visits, resulting in lower search costs and higher customer satisfaction. Thus, this study hypothesizes as below.

\section{H3: Integrated product and pricing information management gives a positive influence on customer satisfaction.}

Free and convenient information access lead to customer's increased self-efficacy toward shopping. For example, Voss and Grewal [42] show that greater internet access is positively and actively related to online channel selection. Also, according to Melero et al. [25], 39\% of customers are very doubful to visit a store if the store does not offer information about the physical store's inventory status. In order for consumers to perceive higher shopping values, 
information needs to be integrated, and higher shopping values are related to satisfaction. Thus, this study hypothesizes as below.

\section{H4: Integrated information access gives a positive influence on customer satisfaction.}

The fulfillment process is linear in $\mathrm{OC}$ since retailers have placed the distribution system on the front line. If the order is placed on the promise of the retailer, this reliable process will give the customer a positive attitude [4]. The outcome is a matter of trust and commitment between the customer and the business, and dissatisfaction will arise if the order is not correctly maintained. Thus, this study hypothesizes as below.

\section{H5: Integrated order fulfillment gives a positive influence on customer satisfaction.}

In general, retailers with multi-channels can effectively manage their integrated customer service operations and are deemed to be capable of fulfilling the consumers' need [29], [43]. Customers use multi-channel not only to purchase products and services, but also to contact the retailer for other purposes, including information seeking, asking advice, and assuring the availability of the products [27]. More customer contacts will help to meet the diverse needs of customers. As a result, OC's multiple touch points and customer support will have a positive impact on customer satisfaction. Also, as a way to promote customer service in OC, return logistics capabilities must be prepared. Most customers demand an easy and convenient return service, which is vital to customer service [14], [19]. Thus, this study hypothesizes as below.

H6: Integrated customer service gives a positive influence on customer satisfaction.

\subsection{Satisfaction and Shopping Behavior}

The OC shopping environment provides retailers with many advantages to improve customer experience. In a variety of previous studies, customer satisfaction has been identified as a key predictor of positive customer behavior. The relationship between satisfaction and positive behavior has been confirmed repeatedly by several researchers [1], [9], [40]. Satisfaction is understood as an ongoing evaluation of the surprise inherent in consumption experience, and a satisfied consumer is more likely to develop a closer relationship and more likely to take steps to fortify dependence to the firm [30]. Thus, this study hypothesizes as below.

\section{H7: Customer satisfaction gives a positive influence on the intention to revisit OC.}

\subsection{Moderating Role of PC}

Customer differences in psychographics and value perception are essential factors affecting channel behavior [27]. Zeithaml [49] defines value as the consumer's overall assessment of the utility of a product based on perceptions of what is received and what is given. The importance of consumer value in retailing sector stems from the fact that it is compared between retailers. Among the perceived values, this research focuses on perceived convenience (PC) as the individual consumer moderating variable that tends to either accentuate or reduce the impact of $O C$ characteristics on customer satisfaction because perceived convenience is one of the significant factors that motivate consumers towards shopping [15]. Thus, depending on the degree to which OC's integrated efforts are perceived as convenient, the channel's performance will vary. Thus, this study hypothesizes as below.

H8: The relations between OC characteristics and customer satisfaction are moderated by perceived shopping convenience.

\section{Methodology and Result}

This research focuses on omni consumers, who use online touchpoints and physical stores of a particular retailer, in order to explore consumers' shopping experience. For further study, this research identifies omni consumers by channel selection behavior during their shopping experience. The respondents are required to describe their most recent $\mathrm{OC}$ shopping experiences in both physical stores and e-commerce stores of an OC retailer before they participate in the survey.

\subsection{Measurement and Sample}

Measurement items in the model were borrowed from the previous studies for initial validity and then translated to fit in the Korean consumer context. As a next step, a set of defined constructs and related items was submitted to a group of academicians to test face validity. The constructs and items to describe the characteristics of OC were borrowed from the original questions of Wolfinbarger and Gilly [44] and Oh et al. [29]. Part of these questions was modified regarding the context of the Korean market. The items to evaluate customer satisfaction and intention to revisit OC were borrowed from Hausman and Siekpe [17], and Lin and Wang [24]. Figure 2 illustrates the research model, and Table 1 shows the constructs and items used in the study. 


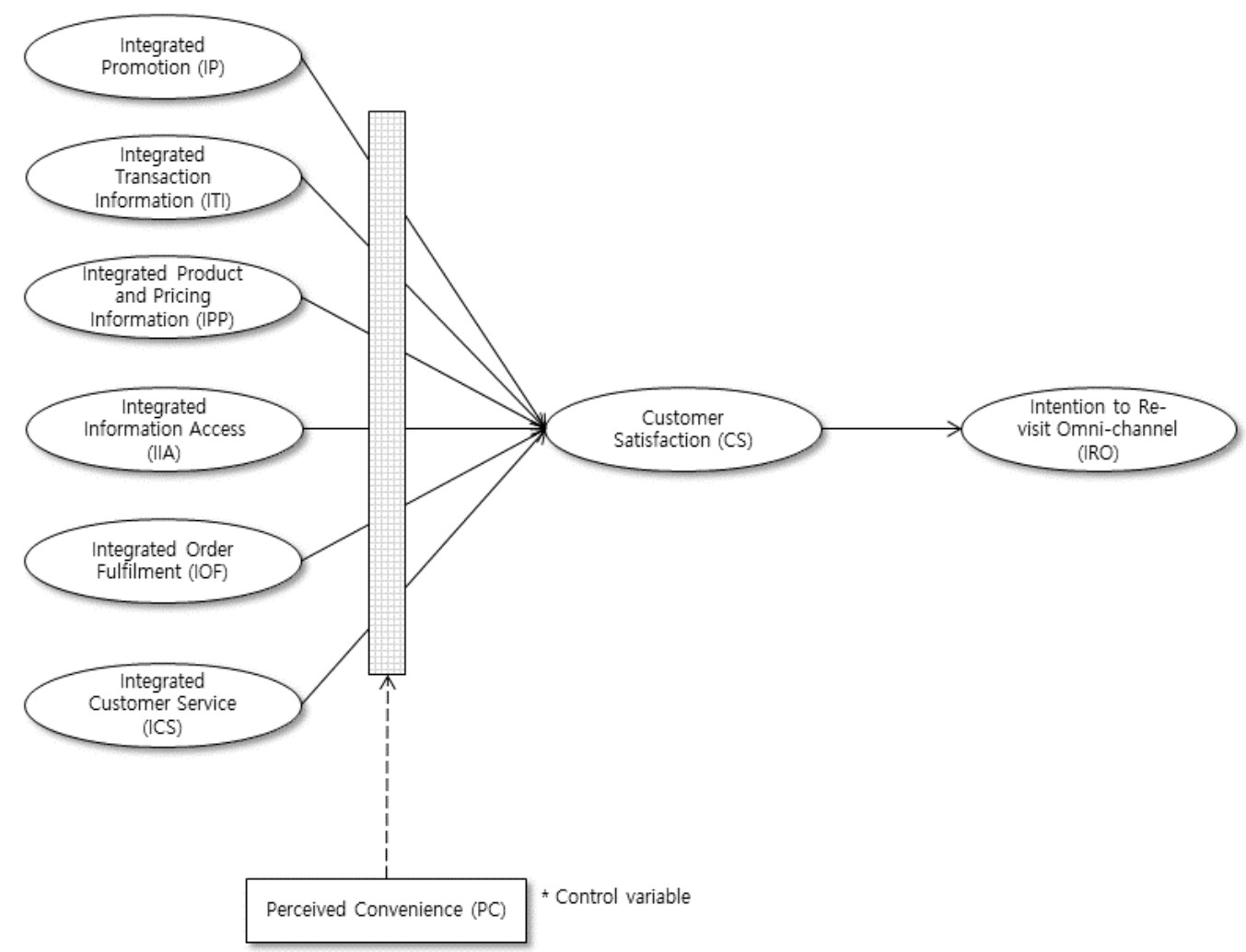

Figure 2: Research model

Table 1: Construct and item

\begin{tabular}{|c|c|}
\hline Construct & Items \\
\hline \multirow{3}{*}{$\begin{array}{l}\text { Integrated } \\
\text { Promotion } \\
\text { (IP) [29], [44] }\end{array}$} & $\begin{array}{l}\text { a1. The website highlights in-store promotions that are taking place in the } \\
\text { physical store }\end{array}$ \\
\hline & $\begin{array}{l}\text { a2. The website advertises the physical store by providing address and contact } \\
\text { information of the physical store }\end{array}$ \\
\hline & $\begin{array}{l}\text { a3. The physical store advertises the website through pamphlets, receipts, and } \\
\text { carrying bags }\end{array}$ \\
\hline \multirow{4}{*}{$\begin{array}{l}\text { Integrated } \\
\text { Transaction } \\
\text { Information } \\
\text { (ITI) [29], [44] }\end{array}$} & $\begin{array}{l}\text { a4. The firm keeps an integrated purchase history of customers' online and } \\
\text { offline purchases }\end{array}$ \\
\hline & a5. The firm allows customers to access their prior integrated purchase history \\
\hline & $\begin{array}{l}\text { a6. The firm makes future purchase recommendations to customers based on } \\
\text { past consolidated online and offline purchases }\end{array}$ \\
\hline & $\begin{array}{l}\text { a7. The website customizes Web pages for customers based on past } \\
\text { consolidated online and offline purchases }\end{array}$ \\
\hline \multirow{3}{*}{$\begin{array}{l}\text { Integrated } \\
\text { Product \& } \\
\text { Pricing } \\
\text { Information } \\
\text { (IPP) [29], [44] }\end{array}$} & $\begin{array}{l}\text { a8. Information on stock availability is consistent in both the physical store and } \\
\text { website }\end{array}$ \\
\hline & a9. Product/service prices are consistent in both the physical store and website \\
\hline & a10. Discounts are consistent in both the physical store and website \\
\hline \multirow{4}{*}{$\begin{array}{l}\text { Integrated } \\
\text { Information } \\
\text { Access } \\
\text { (IIA) [29], [44] }\end{array}$} & $\begin{array}{l}\text { a11. The firm allows checking of inventory status at the physical store through } \\
\text { the website }\end{array}$ \\
\hline & $\begin{array}{l}\text { a12. The physical store provides Internet kiosks for customers to access the } \\
\text { information and functionalities available on the website }\end{array}$ \\
\hline & $\begin{array}{l}\text { a13. The physical store provides Internet kiosks for customers to access store } \\
\text { maps to quickly locate items in the store }\end{array}$ \\
\hline & $\begin{array}{l}\text { a14. The physical store provides Internet kiosks for customers to find answers to } \\
\text { frequently asked questions without making enquiries from in-store customer } \\
\text { service assistants }\end{array}$ \\
\hline
\end{tabular}




\begin{tabular}{|l|l|}
\hline \multicolumn{2}{|l|}{ Table 1: continuation } \\
\hline $\begin{array}{l}\text { Integrated Order } \\
\text { Fulfillment } \\
\text { (IOF) [29], [44] }\end{array}$ & $\begin{array}{l}\text { a15. The website allows ordering by a catalog number } \\
\text { a16. The physical store provides internet kiosks for customers to place orders for } \\
\text { out-oftock items }\end{array}$ \\
\hline \multirow{4}{*}{$\begin{array}{l}\text { Integrated } \\
\text { Customer } \\
\text { Service (ICS) } \\
\text { [29], [44] }\end{array}$} & $\begin{array}{l}\text { a17. The in-store customer service center accepts return, repair or exchange of } \\
\text { products purchased online }\end{array}$ \\
\cline { 2 - 2 } & $\begin{array}{l}\text { a18. The website provides post-purchase services such as support for the } \\
\text { products purchased at physical stores }\end{array}$ \\
\cline { 2 - 2 } & $\begin{array}{l}\text { a19. The website provides interactive access to the customer service assistant } \\
\text { through a real-time chat program }\end{array}$ \\
\hline $\begin{array}{l}\text { Customer } \\
\text { Satisfaction } \\
\text { (CS) [17] }\end{array}$ & b1. I am satisfied with this OC \\
\cline { 2 - 2 } $\begin{array}{l}\text { Intention to } \\
\text { Revisit OC } \\
\text { (IRO) [24] }\end{array}$ & b3. The OC is successful \\
\cline { 2 - 2 } & b4. I am likely to revisit the channel in the near future \\
\cline { 2 - 2 } & b5. I am encouraged to revisit the channel in the near future \\
\hline
\end{tabular}

A Google survey website was constructed to help data collection. The questionnaire includes a set of demographic information, including age, gender, and other respondent's background information. An e-mail invitation was sent to potential respondents, containing an embedded link to the site hosting the Google survey. Those respondents were college students who had been attending online K-MOOC (Korean massive open online courses). In 2018, Korea had a smartphone penetration rate of over 100 percent. In particular, members of the young generation are the fastest adopters of new technologies, and acceptance of OCs is no exception to them. Also, they are highly homogeneous groups and were considered appropriate for the survey. To test for nonresponse bias, we compared the demographic information of the respondents in the process of data collection and found no significant differences.

A total of 479 respondents has completed the online survey successfully. They range in age from 18 to 28 , with a mean age of 22.54 years. Of the entire sample, $54.1 \%$ are male, and $45.9 \%$ are female. All respondents have experienced at least one time of omni-shopping, and on average they spend $270 \$$ for shopping every month.

\subsection{Reliability and Validity}

It is important to test the reliability and validity of the variables to complete the hypothesis test. The criteria to measure internal consistency is by calculating Cronbach's alpha and other key coefficients. Cronbach's alpha and composite reliability should be higher than 0.6. In this test, both the alpha scores and composite reliability coefficients are all above the required criteria except IOF, which has a Cronbach's alpha score lower than the criteria. However, other reliability indices such as composite reliability and AVE are within the criteria and are considered to be acceptable. The results are shown in Table 2.

Table 2: Reliability analysis

\begin{tabular}{|l|l|l|l|}
\hline $\begin{array}{l}\text { Construct } \\
\text { (cut-off criteria) }\end{array}$ & $\begin{array}{l}\text { Cronbach's alpha } \\
(<0.6)\end{array}$ & $\begin{array}{l}\text { Composite reliability } \\
(<0.6)\end{array}$ & $\begin{array}{l}\text { AVE } \\
(<0.5)\end{array}$ \\
\hline IP & .662 & .812 & .591 \\
\hline ITI & .801 & .866 & .618 \\
\hline IPP & .753 & .854 & .662 \\
\hline IIA & .839 & .864 & .613 \\
\hline IOF & .521 & .807 & .676 \\
\hline ICS & .684 & .819 & .603 \\
\hline CS & .877 & .924 & .802 \\
\hline IRV & .870 & .921 & .795 \\
\hline
\end{tabular}

Besides, factor analysis is performed to test the validity of the constructs. This analysis uses the PCA (principal component analysis) option with VARIMAX rotation. In the test, six factors explaining $67.02 \%$ of total variance were extracted as expected (See Table 3). 
Table 3: Factor analysis of exogenous variables

\begin{tabular}{|l|l|l|l|l|l|l|}
\hline & IIA & ITI & IPP & ICS & IP & IOF \\
\hline a13 & 0.860 & 0.197 & 0.155 & 0.097 & 0.113 & 0.065 \\
\hline a12 & 0.846 & 0.169 & 0.134 & 0.167 & 0.108 & 0.089 \\
\hline a14 & 0.818 & 0.195 & 0.195 & 0.130 & 0.065 & 0.029 \\
\hline a11 & 0.407 & 0.164 & 0.171 & 0.206 & 0.202 & 0.332 \\
\hline a6 & 0.258 & 0.783 & 0.070 & 0.179 & 0.095 & -0.037 \\
\hline a7 & 0.325 & 0.720 & 0.066 & 0.190 & 0.025 & 0.109 \\
\hline a4 & 0.065 & 0.708 & 0.159 & 0.094 & 0.259 & 0.187 \\
\hline a5 & 0.090 & 0.682 & 0.069 & 0.058 & 0.278 & 0.146 \\
\hline a9 & 0.121 & 0.021 & 0.896 & 0.119 & 0.052 & 0.068 \\
\hline a10 & 0.204 & 0.140 & 0.855 & 0.145 & -0.019 & 0.081 \\
\hline a8 & 0.306 & 0.268 & 0.486 & 0.097 & 0.237 & -0.001 \\
\hline a17 & 0.237 & 0.000 & 0.207 & 0.740 & 0.063 & 0.111 \\
\hline a18 & -0.031 & 0.219 & 0.078 & 0.720 & 0.137 & 0.250 \\
\hline a19 & 0.236 & 0.231 & 0.068 & 0.700 & 0.116 & 0.022 \\
\hline a2 & 0.126 & 0.082 & -0.040 & 0.114 & 0.836 & 0.016 \\
\hline a1 & -0.006 & 0.236 & 0.131 & 0.001 & 0.670 & 0.277 \\
\hline a3 & 0.207 & 0.264 & 0.090 & 0.213 & 0.622 & -0.039 \\
\hline a16 & 0.288 & 0.136 & -0.035 & 0.099 & 0.022 & 0.762 \\
\hline a15 & -0.077 & 0.087 & 0.126 & 0.166 & 0.109 & 0.759 \\
\hline Eigen value & 6.222 & 1.783 & 1.439 & 1.233 & 1.049 & 1.008 \\
\hline Eigen value (rotated) & 2.885 & 2.580 & 2.016 & 1.874 & 1.965 & 1.515 \\
\hline Variance\% & 32.746 & 9.386 & 7.575 & 6.487 & 5.522 & 5.303 \\
\hline Variance \% (rotated) & 15.185 & 13.581 & 10.61 & 9.862 & 9.811 & 7.972 \\
\hline Total Variance \% & $67.02 \%$ & & & & & \\
\hline & & & & & &
\end{tabular}

The Fornell-Larcker test is also performed to check discriminant validity, as shown in Table 4. Fornell and Larcker [10] suggested that the square root of AVE (average variance extracted) could be used for evaluating discriminant validity when the calculated value is more significant than other correlation values among the latent variables. In the table, the square root of IIA is .783, and this number is larger than the correlations in the column of IIA $(.335, .371, .491, .211, .491, .227)$, and also larger than those in the row of IIA (.444). Similar results are also made for other constructs, indicating the discriminant validity is well established.

Table 4: Fornell-Larcker test

\begin{tabular}{|l|l|l|l|l|l|l|l|l|}
\hline & ICS & IIA & IOF & IP & IPP & IRV & ITI & CS \\
\hline ICS & 0.777 & & & & & & & \\
\hline IIA & 0.444 & 0.783 & & & & & & \\
\hline IOF & 0.365 & 0.335 & 0.822 & & & & & \\
\hline IP & 0.353 & 0.371 & 0.275 & 0.769 & & & & \\
\hline IPP & 0.361 & 0.491 & 0.227 & 0.281 & 0.814 & & & \\
\hline IRV & 0.281 & 0.211 & 0.384 & 0.391 & 0.132 & 0.891 & & \\
\hline ITI & 0.441 & 0.491 & 0.313 & 0.500 & 0.381 & 0.325 & 0.786 & \\
\hline CS & 0.277 & 0.227 & 0.348 & 0.334 & 0.181 & 0.689 & 0.292 & 0.896 \\
\hline
\end{tabular}

\subsection{Hypothesis Test}

A path model to identify the proposed hypotheses is tested by using the PLS-SEM (partial least squares structural equation method). PLS-SEM is an emerging multi-variate analysis technique that can test additive causal models [45], [46]. Compared to CB-SEM (covariance-based SEM), which is widely used, PLS-SEM can be an excellent alternative to CB-SEM when the conditions such as small sample size and little previous theory are encountered [45]. PLS-SEM is considered to be a suitable method in this research because of the lack of previous empirical study about OC. 
Having established the reliability and validity of constructs, we move to the next step to test the model for the hypothesized paths, using a bootstrap sampling method. Table 5 and Figure 3 show path coefficients for each path and the corresponding t-values (t-value $>1.96=\mathrm{p}<0.05$ ). According to the test results, $\mathrm{H} 1$ (IP $\rightarrow \mathrm{CS}$ ), H5 (IOF $\rightarrow$ $\mathrm{CS})$, and $\mathrm{H} 7$ (CS $\rightarrow \mathrm{IRV})$ are accepted as expected. However, the other four hypotheses $(\mathrm{H} 2 \sim \mathrm{H} 4$ and $\mathrm{H} 6)$ are not accepted at the significance level of 0.05 . An examination of $r^{2}$ value shows that the model shows a substantial amount of the variance. The $r^{2}$ values of CS and IRV are 0.196 and 0.475 , respectively.

Table 5: Hypothesis test

\begin{tabular}{|l|l|l|l|l|}
\hline Hypothesis & Path coefficient & SD & t-value & p-value $\left.{ }^{*}<0.05\right)$ \\
\hline $\mathrm{H} 1 . \mathrm{IP} \rightarrow \mathrm{CS}$ & 0.198 & 0.056 & 3.531 & $0.000^{*}$ \\
\hline $\mathrm{H} 2 . \mathrm{ITI} \rightarrow \mathrm{CS}$ & 0.081 & 0.061 & 1.333 & 0.183 \\
\hline $\mathrm{H} 3 . \mathrm{IPP} \rightarrow \mathrm{CS}$ & 0.015 & 0.053 & 0.283 & 0.777 \\
\hline $\mathrm{H} 4 . \mathrm{IIA} \rightarrow \mathrm{CS}$ & -0.011 & 0.059 & 0.179 & 0.858 \\
\hline $\mathrm{H} 5 . \mathrm{IOF} \rightarrow \mathrm{CS}$ & 0.238 & 0.054 & 4.364 & $0.000^{*}$ \\
\hline $\mathrm{H} 6 . \mathrm{ICS} \rightarrow \mathrm{CS}$ & 0.085 & 0.053 & 1.604 & 0.109 \\
\hline $\mathrm{H} 7 . \mathrm{CS} \rightarrow \mathrm{IRV}$ & 0.689 & 21.281 & $0.000^{*}$ \\
\hline $\mathrm{r}^{2}$ value & $\mathrm{CS}=0.196, \mathrm{IRV}=0.475$ & & \\
\hline
\end{tabular}

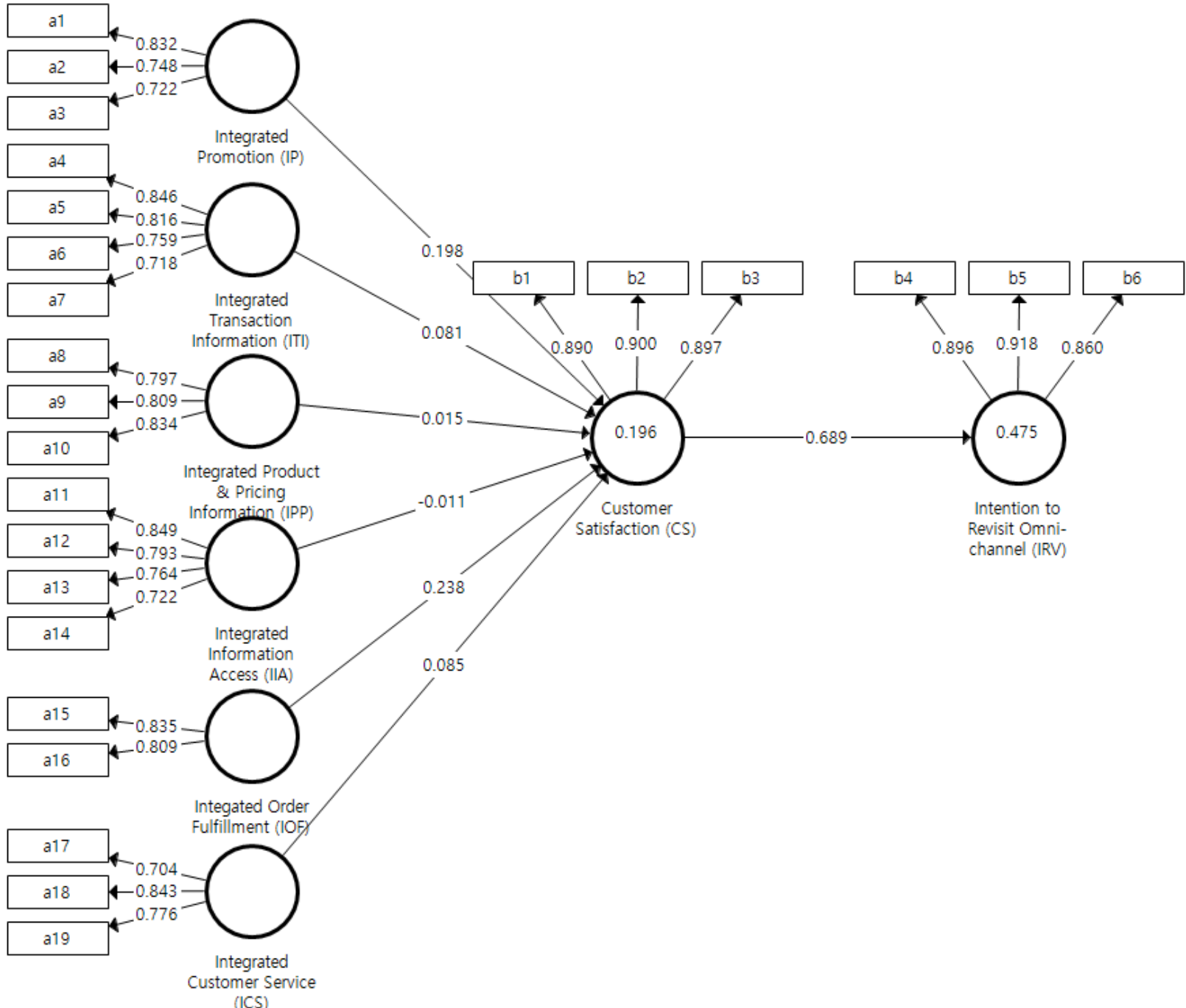

Figure 3: Analysis output 


\subsection{Moderating Effect of Convenience Value}

In addition, the moderation effect of perceived convenience (PC) is tested. When the moderation effect is present, the strength of a relationship between two constructs depends on a third variable. In this research, the relationship between OC characteristics and CS is not the same for all customers but differs depending on their perceived convenience level. If the moderation effect exists, it is seen as a mean to explain heterogeneity in the data. In the previous description, we hypothesized that OC-CS link is significantly influenced by PC. This study measured perceived convenience (PC) with three items that asked a level of convenience toward time, place, and excursion that one feels when pursuing a shopping task in OC channel [18].

As seen in Table 6, we found that PC positively moderated the relationship between IPP and CS (path coefficient $=0.074, p<0.05$ ). However, other expected moderation effects were not significant. Also, the calculated effect sizes $\left(\mathrm{f}^{2}\right)$ are petite. By convention, $\mathrm{f}^{2}$ effect sizes of $0.02,0.15$, and 0.35 are understood small, medium, and large respectively. According to the analysis results of this moderation effect, it is possible that CS will not be increased even if the characteristics of existing OC channel are provided more conveniently. It is also a result of showing the possibility that $\mathrm{OC}$ characteristics are perceived by customers to be irrelevant to their shopping tasks.

Table 6: Moderating effect

\begin{tabular}{|l|l|l|l|l|l|}
\hline $\begin{array}{l}\text { Hypothesis } \\
\text { (interaction) }\end{array}$ & $\begin{array}{l}\text { Path } \\
\text { coefficient }\end{array}$ & SD & $\begin{array}{l}\text { Effect size } \\
\left(\mathrm{f}^{2} \text { value }\right)\end{array}$ & t-value & $\begin{array}{l}\mathrm{p} \text {-value } \\
\left({ }^{*}<0.1,{ }^{* *}<0.05\right)\end{array}$ \\
\hline $\mathrm{H} 8-1 . \mathrm{IP}{ }^{*} \mathrm{PC}$ & 0.046 & 0.040 & 0.003 & 1.141 & 0.254 \\
\hline $\mathrm{H} 8-2 . \mathrm{ITI}{ }^{*} \mathrm{PC}$ & -0.013 & 0.037 & 0.000 & 0.352 & 0.725 \\
\hline $\mathrm{H} 8-3 . \mathrm{IPP}{ }^{*} \mathrm{PC}$ & 0.074 & 0.038 & 0.007 & 1.979 & $0.048^{* *}$ \\
\hline $\mathrm{H} 8-4 . \mathrm{IIA}{ }^{*} \mathrm{PC}$ & 0.071 & 0.046 & 0.007 & 1.544 & 0.121 \\
\hline $\mathrm{H} 8-5 . \mathrm{IOF}{ }^{*} \mathrm{PC}$ & -0.057 & 0.032 & 0.006 & 1.813 & $0.070^{*}$ \\
\hline $\mathrm{H} 8-6 . \mathrm{ICS}{ }^{*} \mathrm{PC}$ & 0.038 & 0.044 & 0.001 & 0.860 & 0.390 \\
\hline
\end{tabular}

\section{Discussion}

Based on our research model and test results, this chapter will elaborate on the conclusion of our study and propose further research issues.

\subsection{Implications}

OC can eliminate marketing silos that reduce organizational efficiency, while the firm expects a seamless experience across the internet and physical worlds [12]. In the new age of OC, it is vital for academics and practitioners to understand the characteristics and consequences of OC strategy. This research investigates antecedents, which will influence customer satisfaction and behavioral intention. According to the results, strong evidence does not exist between $\mathrm{OC}$ factors and CS. Among the six hypotheses explaining the major characteristics of OC strategy, only two OC factors are identified to be significantly important to CS. The result is not satisfactory but has critical academic and managerial implications.

First, retailers need to adopt a customer-oriented focus to be a successful OC retailer. In this research, the relationship between customer satisfaction and intention to revisit is supported strongly. Since the introduction of the OC concept in retailing, we have assumed that the OC will contribute to customer satisfaction without any clear empirical evidence and it is now undoubtedly firmly established that satisfaction is a factor of the success of a firm, but it is tough to provide integrated customer satisfaction under the OC environment. The focus on OC environment should be on building a successful relationship with customers by providing integrated and positive experiences across the different channels of the retailer. To achieve this goal, a retailer needs changes both in the way of business and in the organizational culture. However, according to the results of the study, OC strategy is more likely to be a strategy based on firm efficiency than customer satisfaction. It is strongly suggested that OC strategies implemented by retailers may require a redesign in terms of customer satisfaction.

Second, we should seriously consider the possibility that existing OC marketing approaches are efforts to increase the efficiency of the firms than to increase customer benefits. This assumption can give a partial explanation of why the major hypotheses are not accepted. Firms can get clear benefits by adopting OC strategy. OC strategy allows retailers to break inefficient organizational silos that separate retailers from their suppliers and increase transparency for all members of the supply chain network. Greater transparency gives retailers the ability to improve their products and services further, increasing their competitive advantage [23]. However, the relative benefits that consumers can gain from OC may not be as clear to consumers.

Third, the integration of possible customer promotion across channels is an essential effort. The key to success in the $\mathrm{OC}$ is to unify touchpoints between retailer and customer and to integrate all consumer experience. Omni 
retailers need to get a total view of their customers' behavior across different type of channels. The integrated efforts to provide IMC (integrated marketing communication) will help retailers to identify the shopping pleasures of omnishoppers and will help to select and maintain loyal customers,

Fourth, customized order fulfillment of customers is matter. Under OC circumstance, customers' order process is very different. For example, the first order process can begin from online or offline touchpoints, which is depending on the individual channel preference. Based on the complexity of omni-shopper, the importance of personal one-toone order fulfillment is increasing, and retailers must create ways to improve the order accuracy and related satisfaction.

Fifth, the hypotheses, which are not supported, give some important questions to the OC strategy. For example, the importance of IPP (integrated product and pricing information) is not supported. Previous studies have concluded that the majority of e-commerce consumers is motivated by the benefit of low prices [1], [37]. However, in an OC environment in which price information is integrated and the price is the same, these existing price seekers are not satisfied. They are disappointed with the elimination of price bargaining opportunities and are likely to express dissatisfaction. This result suggests a possibility that the emotional pleasure of shopping coming from the comparison of price or cheap purchase opportunity is underestimated in OC strategy. It is necessary to recognize the importance of hedonic factor to shopping behavior and to try to reflect it in changing shopping environment.

Sixth, according to the test result of the moderating effect, the perceived convenience (PC) is significantly controlling the relationship between IPP and CS, and the path coefficient value is positive. This result shows that the convenience of the $\mathrm{OC}$ channel plays a vital role in improving consumer satisfaction by helping consumers to compare the price and product in different stores more efficiently. Among the OC characteristics, The results show that the most important motivation for consumers to visit the OC channel is the possibility of comparing products and prices of online and offline stores. As a result, retailers will need to install more information kiosks, proper space for product experiences, and provide accurate comparison catalogs in order to enhance convenience for consumers.

\subsection{Limitations and Further Research}

There are a few limitations to this research that should be noted when understanding its findings. First, generalizability is an issue that applies to most distribution studies, and this research is no exception. Considering the local characteristics of the distribution industry, we found research limitations as a domestic study. A comparative study considering the global market situation and contexts needs to be conducted in the future.

Second, in this research, the product type that may make a difference in the relationships between OC characteristics and CS were not included. Among many factors that influence channel choice, product type, either hedonic or utilitarian, plays an important role in the consumer decision-making process and needs to be considered in the research model.

Third, online questionnaires were collected at one point in time and via one method. According to Straub et al. [36], the potential for common method variance exists in that case. Common method variance might bring a potential statistical issue since respondents were asked to evaluate all questions at once. To prevent common method variance issue, we selected respondents who had enough $\mathrm{OC}$ experiences during the past twelve months, and their subjective OC visit frequencies were also evaluated by using a Likert scale. However, other methods, including direct observation and analysis of actual shopping behavior via log files, could be used to offer a richer understanding of $\mathrm{OC}$ and to overcome potential data bias from common method variance.

Fourth, the results of this study were obtained using college student subjects. These results may be somewhat different from results using other demographic groups. It is important to state that different consumers have different needs and requirements. However, the majority of internet research utilizes college students as their subject pool because they are so-called 'digital natives' [16], [32]. In this study context, college subjects are preferred as they are more likely to be shopping in OC.

Fifth, the reliability of the measurement used in this study will need to be strengthened. For example, Cronbach's alpha value of IOF was less than 0.6 and was included in the analysis of the empirical model. The fact reveals the limitation of the initial study on $\mathrm{OC}$ characteristics and shows the necessity of developing more stable measurement tool through the accumulation of future research results. In this regard, additional scale development studies may be needed to understand the characteristics of the OC.

Sixth, we have to perform additional research on the implications of rejected hypotheses. The impact of ITI, IPP, and IIA on CS was not significant. These unexpected consequences may be related to the market fact that the OC is still in the process of evolution, rather than the lack of logic in the theoretical relationship in the research model. We must remind that $\mathrm{OC}$ is still in transition and that the services it provides are not yet meeting customer s' high expectations. As a result, there is a need to re-analyze the model in the future as the OC evolves further.

Considering the limitations of this study, future research directions are as follows. First, comparative studies with other countries where OC channels are active will be needed. Second, we need to take into account the types of product (i.e., hedonic product vs. utilitarian product) or different shopping motivations (i.e., social motivation vs. 
Personal motivation) as a controlling variable. Third, it is necessary to carry out qualitative research methods such as store observation and customer interview in order to understand OC visit motivation more deeply. Fourth, the fact that current $\mathrm{OC}$ is constantly evolving should be admitted. Thus, continuous efforts to explain the new distribution changes through follow-up research should continue.

\section{References}

[1] R. E. Anderson and S. S. Srinivasan, E-satisfaction and e-loyalty: A contingency framework, Psychology \& Marketing, vol. 20, no. 2, pp. 123-138, 2003.

[2] Ansari, C. F. Mela and S. A. Neslin, Customer channel migration, Journal of Marketing Research, vol. 45, no. 1, pp. 60-76, 2008.

[3] N. Beck and D. Rygl, Categorization of multiple channel retailing in multi-. cross-. and omni-channel retailing for retailers and retailing, Journal of Retailing and Consumer Services, vol. 27, pp. 170-178, 2015.

[4] D. R. Bell, S. Gallino and A. Moreno, How to win in an omnichannel world, MIT Sloan Management Review, vol. 56, no. 1, pp. 45, 2014.

[5] T. Bilgicer, K. Jedidi, D. Lehmann, and S. Neslin, Social contagion and customer adoption of new sales channels, Journal of Retailing, vol. 91, no. 2, pp. 254-271, 2015.

[6] L. Cao, Business model transformation in moving to a cross-channel retail strategy: A case study, International Journal of Electronic Commerce, vol. 18, no. 4, pp. 69-96, 2014.

[7] L. Cao and L. Li, The impact of cross-channel integration on retailer's sales growth, Journal of Retailing, vol. 91, no. 2 , pp. 198-216, 2015 .

[8] S. Chopra, How omni-channel can be the future of retailing, Decision, vol. 43, no. 2, pp. 135-144, 2016.

[9] J. J. Cronin and S. A. Taylor, Measuring service quality: A reexamination and extension, Journal of Marketing, vol. 56, no. 3, pp. 55-68, 1992.

[10] C. Fornell and D. Larcker, Evaluating structural equation models with unobservable variables and measurement error, Journal of Marketing Research, vol. 8, no.1, pp. 39-50, 1981

[11] K. H. Frost and S. K. Sullivan. (2015, October) Moving from multi-channel to omni-channel customer engagement: Intelligent interaction analytics are the foundation, Frost and Sullivan. [Online] Available: https://www.qpc.com/wp-content/uploads/2015/10/20150430 Cl WP FS omnichannel cust engagement pub. pdf

[12] G. M. Fulgoni, Omni-channel retail insights and the consumer's path-to-purchase: How digital has transformed the way people make purchasing decision, Journal of Advertising Research, vol. 56, no. 1, pp. 377-380, 2014.

[13] S. Han, Effect on brand loyalty in omni-channel: Focus on category management, Journal of Distribution Science, vol. 15, no. 3, pp. 61-72, 2017.

[14] R. F. Handfield, F. Straube, H. C. Pfohl, and A. Wieland, Key trends shaping the global logistics environment, in Inspiration, Ideas, Innovation (T. Wimmer and S. Hucke, Eds.). Hamburg: DVV Media Group, 2013, pp. 20-48.

[15] A. C. Haridasan and A. G. Fernando, Online or in-store: Unravelling consumer's channel choice motives, Journal of Research in Interactive Marketing, vol. 12, no. 2, pp. 215-230, 2018.

[16] K. Hassanein and M. Head, Manipulating perceived social presence through the web interface and its impact on attitude towards online shopping, International Journal of Human-Computer Studies, vol. 65, no. 8, pp. 689708, 2007.

[17] A. V. Hausman and J. S. Siekpe, The effect of web interface features on consumer online purchase intentions, Journal of Business Research, vol. 62, no. 1, pp. 5-13, 2009.

[18] K. Hiraishi, H. Ito, Y. Inoue, K. Eto, N. Katashio, S. Koike, Y. Go, C. D. Park, H. Hayashi, R. Yoneyama, and I. Takahashi, The effect of omni channel retailer's strategy on store loyalty, in Proceedings SMA (Society for Marketing Advances), Atlanta, 2016, pp. 441-447.

[19] A. Hüber, A. Holzapfel and H. Kuhn, Distribution systems in omni-channel retailing, Business Research, vol. 9, no. 2, pp. 255-296, 2016.

[20] E. Juaneda-Ayensa, A. Mosquera and Y. S. Murillo, Omnichannel customer behavior: key drivers of technology acceptance and use and their effects on purchase intention, Frontiers in Psychology, vol. 7, pp. 1-11, 2016.

[21] G. Lawrie. (2015, March). The retail CIO agenda 2015: Secure and innovate, Forrester Research, Inc., 2015. [Online] Available: https://www.forrester.com/report/The+Retail+ClO+Agenda+2015+Secure+And+Innovate/-/ERES121188

[22] H. Lee and K. K. Leonas, Consumer experiences, the key to surviving in an omni-channel environment: Use of virtual technology, Journal of Textile and Apparel, Technology and Management, vol. 10, no. 3, pp. 1-23, 2018.

[23] J. Lewis, P. Whysall and C. Foster, Drivers and technology-related obstacles in moving to multichannel retailing, International Journal of Electronic Commerce, vol. 18, no. 4, pp. 43-68, 2014.

[24] $\mathrm{H}-\mathrm{H}$. Lin and Y-S. Wang, An examination of the determinants of customer loyalty in mobile commerce contexts, Information \& Management, vol. 43, no. 3, pp. 271-282, 2006.

[25] Melero, F. J. Sese and P. C. Verhoef, Recasting the customer experience in today's omni-channel environment, Universia Business Review, vol. 2nd Quarter, pp. 18-37, 2016.

[26] A. Mollenkopf, E. Rabinovich, T. M. Laseter, and K. K. Boyer, Managing internet product returns: A focus on effective service operations, Decision Sciences, vol. 38, no. 2, pp. 215-250, 2007

[27] S. Neslin, D. Grewal, R. Leghorn, V. Shankar, M. Teerling, J. Thomas, and P. Verhoef, Challenges and opportunities in multichannel customer management, Journal of Service Research, vol. 9, no. 2, pp. 95-112, 2006. 
[28] Z. B. Nsairi, Managing browsing experience in retail stores through perceived value: Implications for retailers, International Journal of Retail \& Distribution Management, vol. 40, no. 9, pp. 676-698, 2012.

[29] L-B. Oh, H-H. Teo and V. Sambamurthy, The effects of retail channel integration through the use of information technologies on firm performance, Journal of Operations Management, vol. 30, no. 5, pp. 368-381, 2012.

[30] R. L. Oliver, Satisfaction: A Behavioral Perspective on the Consumer. New York: McGraw-Hill, 1997.

[31] M. Payne, J. W. Peltier and V. A. Barger, Omni-channel marketing, integrated marketing communications and consumer engagement, Journal of Research in Interactive Marketing, vol. 11, no. 2, pp. 185-197, 2017.

[32] W. Piotrowicz and R. Cuthbertson, Introduction to the special issue information technology in retail: Toward omnichannel retailing, International Journal of Electronic Commerce, vol. 18, no. 4, pp. 5-16, 2014.

[33] A. Rosenmayer, L. McQuilken, N. Robertson, and S. Ogden, Omni-channel service failures and recoveries: Refined typology using facebook complaints, Journal of Service Marketing, vol. 32, no. 3, pp. 269-285, 2018.

[34] SAP Technical Staff, Omni-channel vs multi-channel and the future of customer service, CRM Magazine, vol. WP41, pp. 1, 2014.

[35] Statistica, (2019, August) Retail e-commerce sales worldwide from 2014 to 2021, 2018. Statistica. [Online] Available: https://www.statista.com/statistics/379046/worldwide-retail-e-commerce-sales

[36] W. Straub, Validating instrument in MIS research, MIS Quarterly, vol. 12, no. 2, pp.147-170, 1989.

[37] J. Tanaka, The never-ending search for the lowest price, Newsweek, 133, no. 23, pp. 86, 1999.

[38] N. S. Terblanche, Revisiting the supermarket in-store customer shopping experience, Journal of Retailing and Consumer Services, vol. 40, pp. 48-59, 2018.

[39] R. Venkatesan, V. Kumar and N. Ravishanker, Multichannel shopping: Causes and consequences, Journal of Marketing, vol. 71, no. 2, pp. 114-132, 2007.

[40] V. Venkatesh, J. Y. L. Thong and X. Xu, Consumer acceptance and use of information technology: Extending the unifed theory of acceptance and use of technology, MIS Quarterly, vol. 36, no. 1, pp. 157-178, 2012.

[41] P. Verhoef, P. Kannan and J. Inman, From multi-channel retailing to omni-channel retailing: Introduction to the special issue on multi-channel retailing, Journal of Retailing, vol. 91, no. 2, pp. 174-181, 2015.

[42] B. Voss and D. Grewal, Determinants of online channel use and overall satisfaction with a relational, multichannel service provider, Journal of the Academy of Marketing Science, vol. 31, no. 4, pp. 448-458, 2003.

[43] B. D. Weinberg, S. Parise and P. J. Guinan, Multi-channel marketing: Mindset and program development, Business Horizons, vol. 50, no. 5, pp. 385-394, 2007.

[44] M. Wolfinbarger and M. C. Gilly, eTailQ: Dimensionalizing, measuring and predicting retail quality, Journal of Retailing, vol. 79, no. 3, pp. 183-198, 2003.

[45] K. K. Wong, Partial least squares structural equation modeling (PL-SEM) techniques using SmartPLS, Marketing Bulletin, vol. 24, no. 1, pp. 1-32, 2013.

[46] M. Woo, K. Park and B. Y. Jung, An empirical study on the impact of quality oriented corporate culture on sustainability management performances, Journal of Distribution Science, vol. 12, no. 6, pp. 31-39, 2014.

[47] Y. Ye, K. H. Lau and L. K. Y. Teo, Drivers and barriers of omni-channel retailing in China, International Journal of Retailing \& Distribution Management, vol. 46, no. 7, pp. 657-689, 2018.

[48] M. Y. Yim, S. Yoo, P. L. Sauer, and J. H. Seo, Hedonic shopping motivation and co-shopper influence on utilitarian grocery shopping in superstores, Journal of the Academy of Marketing Science, vol. 42, no. 5, pp. 528-544, 2014

[49] V. A. Zeithaml, Consumer perceptions of price, quality, and value: A means-end model and synthesis of evidence, Journal of Marketing, vol. 52, no. 3, pp. 2-22, 1988. 